\title{
Amelogenesis Imperfecta: Transitional Phase of Management
}

\author{
LAA Pradeepika*1, EMUCK Herath ${ }^{2}$ and PR Jayasooriya ${ }^{3}$ \\ ${ }^{1}$ Senior Registrar in Restorative Dentistry, Division of Periodontology, Sri Lanka \\ ${ }^{2}$ Professsor in paedodontics, Division of Paedodontics, Sri Lanka \\ ${ }^{3}$ Department of Oral Pathology, Sri Lanka
}

*Corresponding author: LAA Pradeepika, Division of Periodontology, Faculty of Dental Sciences, Sri Lanka

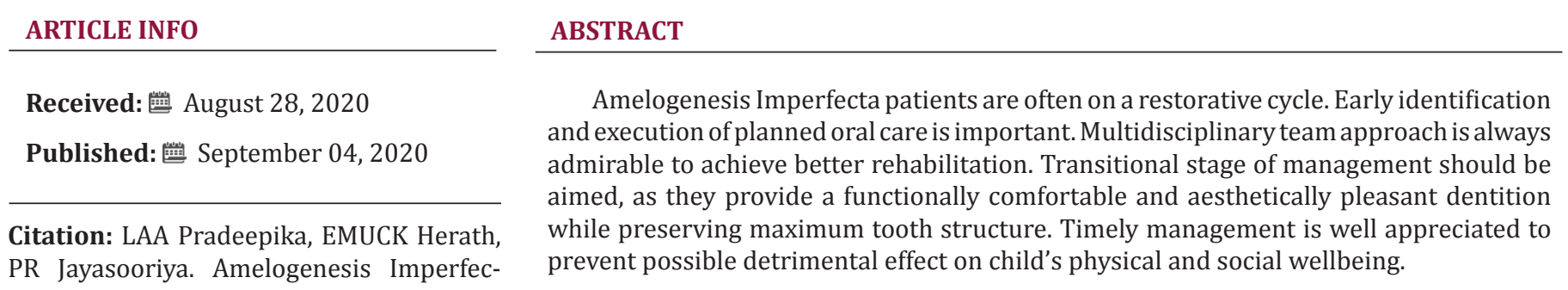

ta: Transitional Phase of Management. Biomed J Sci \& Tech Res 30(1)-2020. BJSTR. MS.ID.004887.

Keywords: Amelogenesis Imperfecta; Transitional phase; Multidisciplinary management

\section{Introduction}

Amelogenesis imperfecta (AI) represents a group of hereditary conditions that is known to cause enamel defects due to single gene mutation[1]. Inheritance patterns in this disease can be autosomal dominant, autosomal recessive, sex linked or sporadic type.Literature reports the prevalence of AI to range from 1:700 to $1: 14000$ [2]. Based on population studies, the suggested average global prevalence of $\mathrm{AI}$ is less than $0.5 \%$ [3]. This rare condition usually affects both primary and permanent dentition with no racial predilection.It is mainly divided into four major groups as hypoplastic, hypocalcification, hypomaturation and hypoplasia-hypomaturation with taurodontism[4]. However, the phenotypic variations are common. Further, there is a probability to coexist different phenotypes in a single patient or on different parts of a single tooth[5]. According to a study done in Sri Lanka, the hypoplastic type bears $45 \%$ while hypomaturation and hypocalcified types represent $30 \%$ and $15 \%$ respectively[6].

Diagnosis of AI is primarily based on clinical and radiological features with possible family history. Histopathology may provide added benefit in phenotypic classification. Unaesthetic teeth due to discoloration, poor surface characteristics, sensitivity and post eruptive enamel breakdown are inherent dental problems in these patients. Collectively, these abnormalities cause greater esthetic and functional problems for patients.This report highlights the importance of transitional management of young children affecting with AI.

\section{Case Report}

A 15-year-old boy presented to the Department of Paedodontics with a complaint of discoloration of teeth. He was unhappy of his unaesthetic teeth and also suffered from dentine sensitivity.He had discolored teeth since childhood and both primary and permanent dentitions were affected. Medical history showed non-significant natal and post-natal periods with good systemic health. Insight into the family history revealed that none of the other family members suffered with the same problem and no consanguinity marriages were present in their family. In general, teeth had rough surfaces with diffused enamel pitting. They presented dispersed white flecks and brown discoloration particularly on the labial surfaces of anterior teeth. Even though the intact enamel was hard on probing, dentine exposed areas were present due to chipping off enamel (Figure 1). He was identified to be of high risk for dental caries with DMFT of [7](Figure 1). 


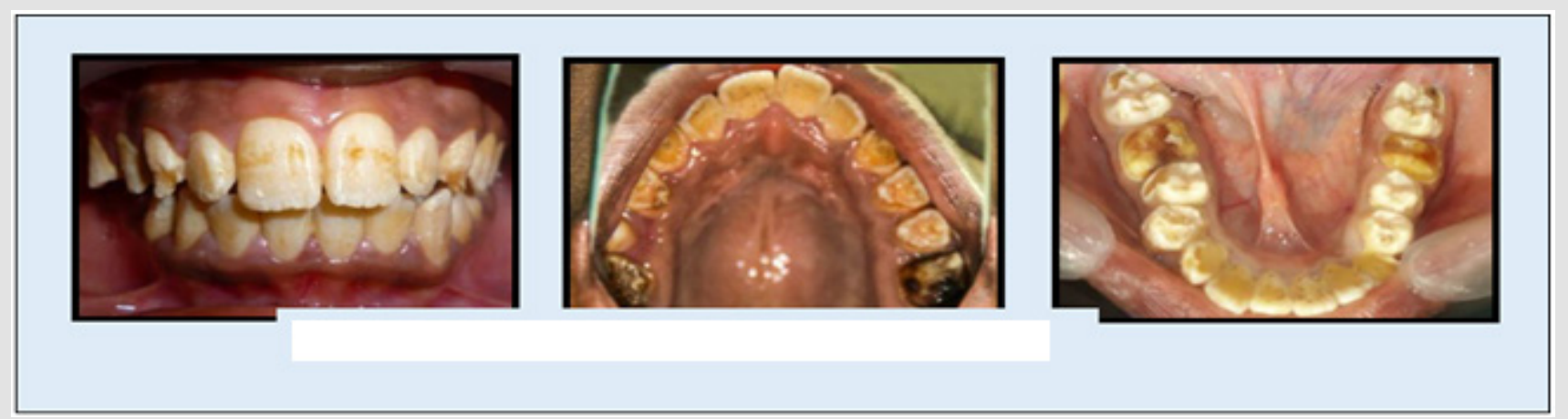

Figure 1: Preoperative presentation of the dentition.

Dental Panoramic Tomogram (DPT) showed all the teeth to be of reduced thickness of enamel with normal radiological contrast between the enamel and dentine. Almost all molar teeth showed pulp stones and presence of taurodontism was excluded (Figure 2).By using the clinical and radiological features, the diagnosis was arrived as "amelogenesis imperfecta - hypoplastic type of sporadic
inheritance".Preventive care was provided and all the teeth which had caries extending to dentine were restored with Composite resin. Root canal treatment of 26 was completed in a single visit (Figure 3). All permanent first molars received Stainless Steel Crown (SSC). Direct veneering with composite resin was performed up to second premolar teeth in the upper and lower arches (Figure 4).

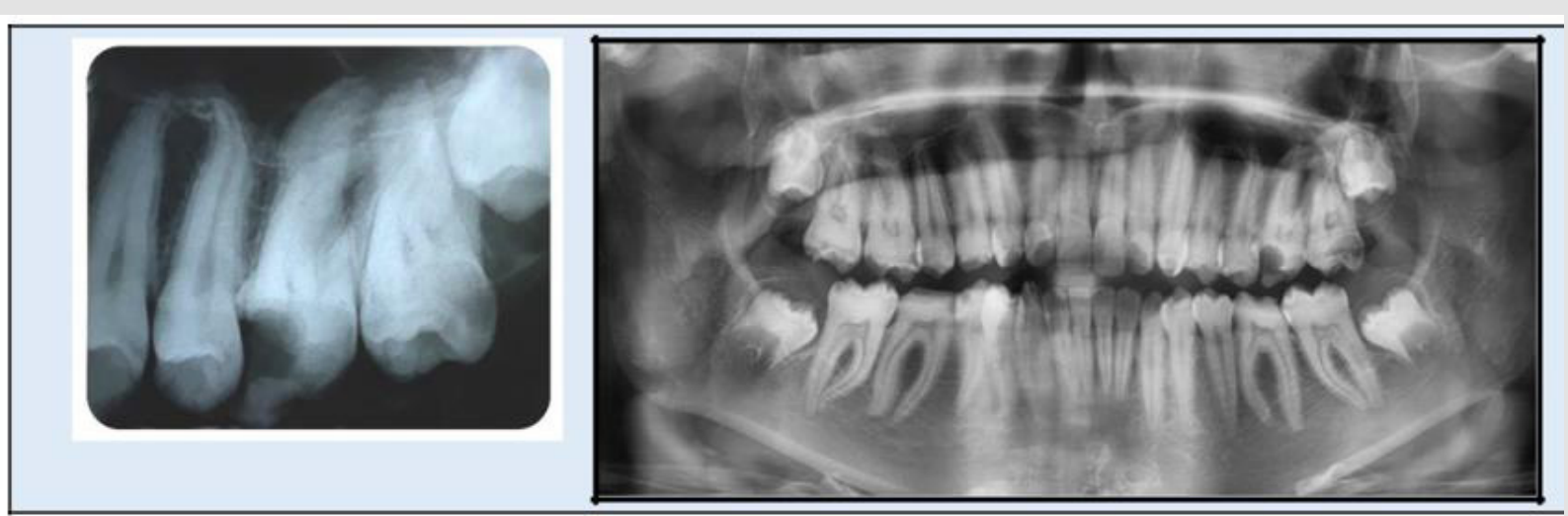

Figure 1: Preoperative radiographs.

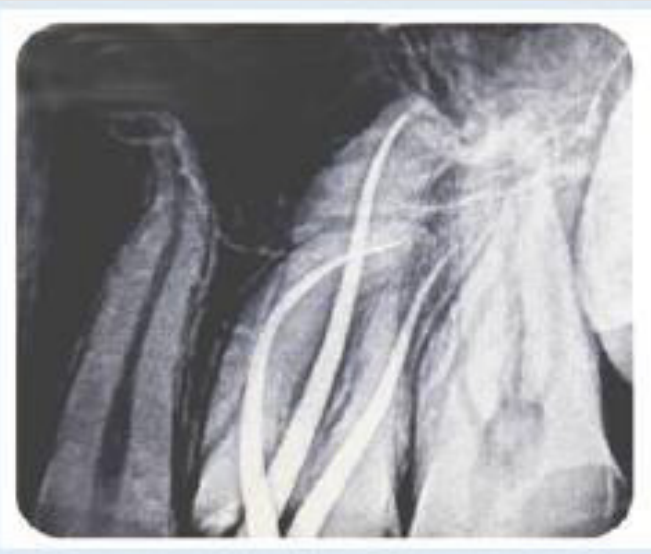

Figure 3: IOPA Radiograph of 26 following RCT. 

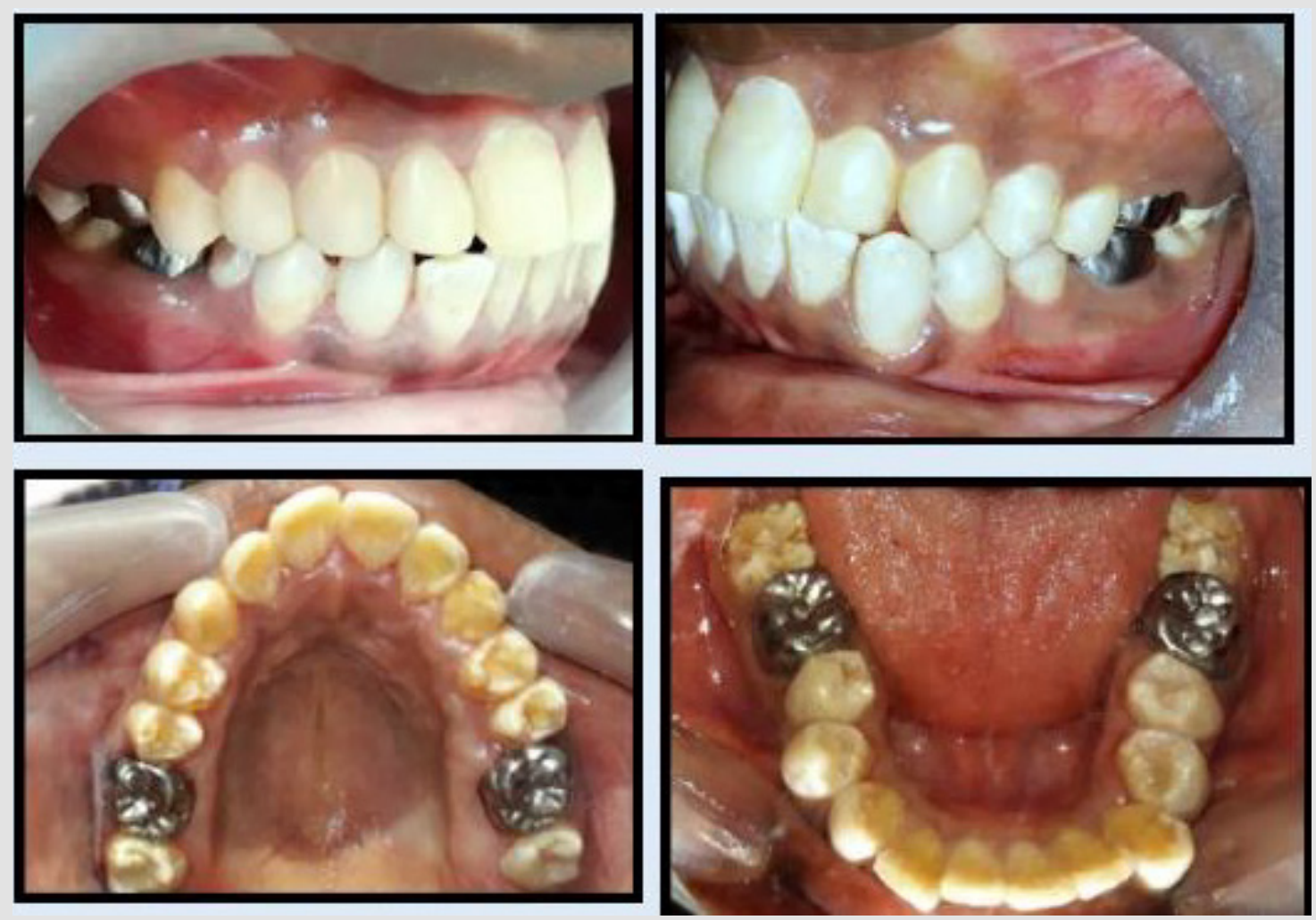

Figure 4: Postoperative appearance of the dentition.

\section{Discussion}

Overall rehabilitation of this cohort of patients comprises timely management depending on their age. It can be categorized as the initial phase where the primary and mixed dentitions are managed, the transitional phase which starts from permanent dentition and continues to the permanent/definitive phase where definitive restorations are carried out in adulthood [7]. The current case describes the transitional phase of management in AI which is important in the success of future restorative care.Prevention is imperative in management to protect individual's own teeth which are structurally compromised. Routine oral hygiene practices and periodic professional care should be provided to achieve good gingival health.Root canal treatment of affected teeth in AI patients may be complicated due to presence of other dental aberrations such as taurodontism or pulp stones. Pulp stones are generally considered as an age-related feature instead of it being pathological[8]. However, according to studies they are commonly associated with teeth in AI [9]. A study by Collins et al. [10] showed that, hypoplastic AI is frequently co-segregated with pulp calcification and impacted teeth. Large pulp stones which occlude the pulp space may hinder the access to root canals, as was in this case. Significantly curved, long roots and the large pulp stone associated with 26 of this child patients added the challenge for endodontic obturation.
Teeth affected with AI should be assessed for necessary protection as soon as eruption of teeth[11]. There has been advancement in dental materials and techniques, in the field of restorative dentistry. This paved the way for improvements in the management aspects for affected dentition.Minimum preparation is invaluable in preserving maximum tooth structure possible. Preformed SSC placed with minimum preparation for permanent molar teeth can function for many years as an interim restoration until a more permanent restorative option is considered[12]. Aesthetics is highly demanded particularly by adolescents who are in a more socially active age. Direct Composite resin restorations are a viable option to renovate aesthetics and eliminate tooth sensitivity[5]. Young permanent teeth have comparatively large pulp chambers and the soft tissues are not matured. Maturation of gingival tissues will expose the tooth structure cervically which might be discolored or malformed. Refurbishment is possible with composite resin to mask exposed cervical area due to gingival maturation. With the advancement of current dentine bonding systems, composite restorations could be predictable in patients with AI5.AI patients should undoubtedly receive long term maintenance care which probably would be lifelong. Reinforcement of oral hygiene, stability of periodontium and occlusal stability should be aimed at regular appointments [11]. 


\section{References}

1. Nathwani N S, Kelleher M (2010) Minimally destructive management of amelogenesis imperfecta and hypodontia with bleaching and bonding. Dent update 37(3): 170-179.

2. Warnakulasuriya S, Tilakaratne WM (2014) Oral Medicine and Pathology; Guide to Diagnosis and Management. Jaypee Brothers Medical Publishers pp. 1-24.

3. Gadhia K, McDonald S, Arkutu N, Malik K (2012) Amelogenesis imperfecta: an introduction. Br Dent J 212(8): 377-9.

4. Witkop CJ (1988) Amelogenesis imperfecta, dentinogenesis imperfecta and dentin dysplasia revisited: problems in classification. J Oral Pathol Med 17(9-10): 547-53.

5. Patel M, McDonnell ST, Iram S, Chan FW-Y (2013) Amelogenesis imperfecta- lifelong management. Restorative management of the adult patient. Br Dent J 215(9): 449-57.

6. Herath EMUCK, Perera I, Jayasooriya PR (2011) Descriptive analysis of sub types of Amelogenesis Imperfecta, based on patients seeking treatment at a Paedodontic clinic. SLDJ 41(01-02): 17-25.

\section{ISSN: 2574-1241}

DOI: 10.26717/BJSTR.2020.30.004887

LAA Pradeepika. Biomed J Sci \& Tech Res

CC (i) This work is licensed under Creative

Submission Link: https://biomedres.us/submit-manuscript.php
7. McDonald S, Arkutu N, Malik K, Gadhiya K, McKaigS (2012) Managing the pediatric patient with amelogenesis imperfecta. Br Dent J 212(9): $425-8$

8. Berkovitz BKV, Holland GR, Moxham BJ (2018) Oral Anatomy, Histology and Embryology. $5^{\text {th }}$ London, UK, pp. 176-94.

9. Poulsen S, Gjorup H, Haubek D, Haukall G, Hintze H, et al. (2008) Amelogenesis imperfecta- a systematic literature review of associated dental and oro-facial abnormalities and their impact on patients. Act Odontol Scan 66(4): 193-9.

10. Collins MA, Mauriello SM, Tyndall DA, Wright JT (1999) Dental anomalies associated with amelogenesis imperfecta: a radiographic assessment. Oral Surg Oral Med Oral Pathol Oral Radiol Endod 88(3): 358-64.

11. Malik K, Gadhia K, Arkutu N, McDonald S, Blair H (2012) The interdisciplinary management of patients with amelogenesis imperfecta - restorative dentistry. Br Dent J 212(11): 537-42.

12. Randall RC (2002) Preformed metal crowns for primary and permanent molar teeth: review of the literature. Pediatr Dent 24(5): 489-500.

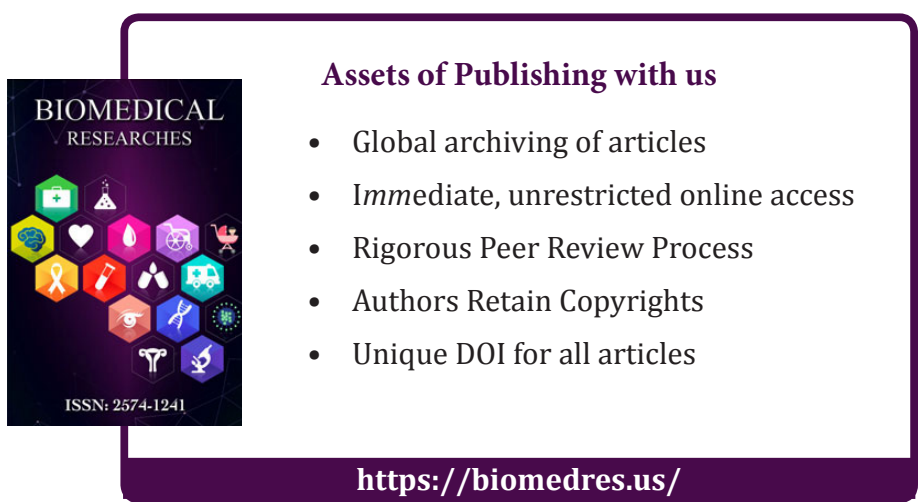

